\title{
Injectable and compression-resistant low- viscosity polymer/ceramic composite carriers for rhBMP-2 in a rabbit model of posterolateral fusion: a pilot study
}

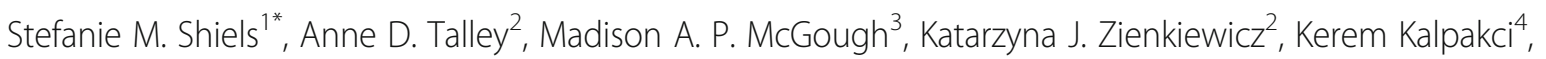
Daniel Shimko ${ }^{4}$, Scott A. Guelcher ${ }^{2,4,5}$ and Joseph C. Wenke ${ }^{1}$

\begin{abstract}
Background: The challenging biological and mechanical environment of posterolateral fusion (PLF) requires a carrier that spans the transverse processes and resists the compressive forces of the posterior musculature. The less traumatic posterolateral approach enabled by minimally invasive surgical techniques has prompted investigations into alternative rhBMP-2 carriers that are injectable, settable, and compression-resistant. In this pilot study, we investigated injectable low-viscosity (LV) polymer/composite bone grafts as compression-resistant carriers for rhBMP-2 in a single-level rabbit PLF model.

Methods: LV grafts were augmented with ceramic microparticles: (1) hydrolytically degradable bioactive glass (BG), or (2) cell-degradable $85 \%$-tricalcium phosphate/15\% hydroxyapatite (CM). Material properties, such as pore size, viscosity, working time, and bulk modulus upon curing, were measured for each LV polymer/ceramic material. An in vivo model of posterolateral fusion in a rabbit was used to assess the grafts' capability to encourage spinal fusion.

Results: These materials maintained a working time between 9.6 and 10.3 min, with a final bulk modulus between 1.2 and 3.1 MPa. The LV polymer/composite bone grafts released 55\% of their rhBMP-2 over a 14-day period. As assessed by manual palpation in vivo, fusion was achieved in all $(n=3)$ animals treated with LV/BG or LV/CM carriers incorporating $430 \mu \mathrm{g} \mathrm{rhBMP-2} / \mathrm{ml}$. Images of $\mu \mathrm{CT}$ and histological sections revealed evidence of bone fusion near the transverse processes.
\end{abstract}

Conclusion: This study highlights the potential of LV grafts as injectable and compression-resistant rhBMP-2 carriers for posterolateral spinal fusion.

Keywords: Posterolateral fusion, Rabbit, Bone morphogenetic protein, Polyurethane, Injectable, Compression resistant

\section{Background}

Spinal fusion surgeries are performed for a variety of ailments, such as disc degeneration, spinal stenosis, and degenerative spondylolisthesis, as well as traumatic injuries [1]. Autograft bone is the current gold standard due to its osteoconductive, osteoinductive, and osteogenic properties. Traditional harvesting sights include the iliac crest and local bone following spinal decompression; however,

\footnotetext{
* Correspondence: stefanie.m.shiels.ctr@mail.mil

'US Army Institute of Surgical Research, Fort Sam Houston, TX, USA Full list of author information is available at the end of the article
}

these involve risk of donor site morbidity or inadequate bone supply.

Synthetic bone grafts have been investigated as alternatives to autograft. The growth factor recombinant human bone morphogenetic protein-2 (rhBMP-2) promotes differentiation, maturation, and proliferation of multipotent cells and thus is approved for clinical use for posterolateral lumbar spinal arthrodesis as either an autograft bone extender or bone graft substitute [2]. Current protocol involves delivery of rhBMP-2 from an absorbable collagen sponge (ACS) from within a compression-resistant 
metallic tapered spinal fusion cage (LT-CAGE ${ }^{\mathrm{Tm}}$, Medtronic, Minneapolis, MN) for interbody fusion [3, 4]. Use of rhBMP-2-loaded ACS in a posterolateral fusion procedure is more challenging than interbody fusion due to the less favorable biological and mechanical conditions for bone healing [5]. Recent studies involving combining the rhBMP-2/ACS with a bulking agent, such as calcium phosphate granules, show improved posterolateral fusion rates in a non-human primate model compared to rhBMP-2/ACS alone, revealing the utility of a compression-resistant rhBMP2 carrier [5-10].

For placement of graft materials, surgical approaches involving large incisions are often used. However, there is no standard methodology for application of grafting materials using minimally invasive surgical techniques (MIS). A MIS spinal fusion approach could potentially decrease both muscle destruction and length of hospital stay. There is considerable interest in the development of new bone grafts that can be delivered by MIS techniques: injectable and, upon curing, are resistant to the compressive forces of the posterior musculature [10]. However, this combination of favorable properties cannot be achieved using currently available carriers.

The goal of this research project was to develop and evaluate the feasibility of a rhBMP-2-loaded ceramic composite. Here, injectable low-viscosity poly(ester urethane)(LV-PUR)/ceramic composite bone grafts are introduced in a rabbit model of posterolateral fusion (PLF). These LV grafts exhibit setting times of 5-10 min [11-13], support diffusion-controlled release of rhBMP2 , and promote healing in rodent, dog, and sheep models of bone regeneration [14-17].

\section{Methods}

\section{Material preparation and characterization}

The LV-PUR/ceramic composite grafts were prepared in a multistep process: (1) preparation of a polyester triol which is the foundation of the LV-PUR, (2) surface modification of the ceramic particles, and (3) combination of the LV-PUR, the ceramic component, and a polymerization catalyst to form a composite graft. Materials were purchased from Sigma-Aldrich (St. Louis, $\mathrm{MO}$ ), Polysciences (Warrington, PA), or Ricerca Biosciences LLC (Painesville, OH), unless otherwise stated. The polyester triol was synthesized as described previously $[18,19]$. The polyester backbone was composed of $70 \%$ E-caprolactone, $20 \%$ glycolide, and 10\% DL-lactide, with a molecular weight of $450 \mathrm{~g} \mathrm{~mol}^{-1}$.

LV-PUR/ceramic composite grafts were augmented with one of two types of ceramic particles to enhance handling properties and to achieve compressionresistant mechanical properties [16]: LV/BG contained 45S5 bioactive glass (BG) particles (150-212 $\mu \mathrm{m}, \mathrm{Mo}-\mathrm{Sci}$ Corporation, Rolla, MO) and the LV/CM contained 85/
$15 \beta$-tricalcium phosphate /hydroxyapatite ceramic (CM) particles (MASTERGRAFT ${ }^{\oplus}$ Mini Granules, Medtronic Spinal and Biologics, Memphis, TN). The surfaces of the BG particles were modified as described previously [20-22], which grafted a $\varepsilon$-caprolactone onto the surface.

To create the LV-PUR/ceramic composite grafts (LV/ BG and LV/CM), the components were mixed in a twostep method [16]. In the first step, the polyester triol, ceramic particles (either $45 \mathrm{wt} \%$ BG or $45 \mathrm{wt} \% \mathrm{CM}$ ), and triethylene diamine (TEDA) in dipropylene glycol (DPG) at $1.1 \mathrm{pphp}$ were combined and mixed by hand for $30 \mathrm{~s}$. Lysine-triisocyanate (LTI-PEG) prepolymer and lyophilized rhBMP-2 (430 $\mu \mathrm{g}$ rhBMP-2/mL cured graft; Medtronic, Memphis, TN) were added to the first step and mixed by hand for $60 \mathrm{~s}$ prior to rheology or placement into a wound. The loading of ceramic particles was $45 \mathrm{wt} \%$, which was the highest possible concentration that maintained injectability [23].

\section{Rheological analysis}

To test the viscosity of the initial composites, triplicate samples were prepared without TEDA catalyst to prevent curing during testing. The polyester triol, LTI-PEG, and ceramic particles were mixed by hand for $60 \mathrm{~s}$ and poured between 40-mm cross-hatched parallel plates on a AR2000ex rheometer (TA Instruments, New Castle, DE). The plates were compressed to a gap of $1000 \mu \mathrm{m}$ and subjected to a dynamic frequency sweep (0.5 to $100 \mathrm{rad} \mathrm{s}^{-1}$ ) at $25{ }^{\circ} \mathrm{C}$ with controlled strain amplitude of $0.02 \%$. A Cox-Merz transformation was applied to the collected dynamic data to obtain the steady state viscosity $(\eta, \mathrm{Pa} s)$ as a function of shear rate $\left(\gamma, \mathrm{s}^{-1}\right)$. The curing profile of the LV-PUR/ceramic composites was also determined using a rheometer. For these, the polyester triol, TEDA catalyst, and ceramic particles were mixed by hand initially for $30 \mathrm{~s}$. The LTI-PEG prepolymer was added, and the samples were mixed by hand for $60 \mathrm{~s}$. Triplicate reactive samples were loaded onto $25-\mathrm{mm}$ disposable aluminum plates and compressed to a gap of $1000 \mu \mathrm{m}$. An oscillatory time sweep was run on triplicate samples with a frequency of $1 \mathrm{~Hz}$ and a controlled amplitude of $1 \%$ strain. The storage $\left(G^{\prime}\right)$ and loss $\left(G^{\prime \prime}\right)$ moduli were collected over time. The working time was defined as the cross-over point of G' and G". The tackfree time (TFT) of LV-PUR/ceramic composite grafts were measured as the time at which the material no longer stuck to a metal spatula.

\section{Porosity and pore size}

Images of cured LV-PUR/ceramic composite specimens were acquired at a voltage of $1 \mathrm{kV}$ using an S-4200 scanning electron microscope (Hitachi, Schaumberg, IL). Diameters of pores, both open and closed, were measured, 
using ImageJ 1.47p image analysis software, of three images for each treatment group. Porosity was determined gravimetrically [18].

\section{Mechanical properties}

Cylindrical samples $(6 \times 12 \mathrm{~mm})$ of cured LV-PUR/ ceramic composites were prepared in the presence of water to mimic in situ curing and tested under compression using an MTS 898 Bionix system (Eden Prairie, MN). Samples were submerged in phosphate-buffered saline for $24 \mathrm{~h}$ prior to testing, preloaded to $3 \mathrm{~N}$, and compressed at a constant rate of $25 \mathrm{~mm} / \mathrm{min}$. Engineering stress was calculated from the original cross-sectional area of the cylinders. The compressive strength was reported as the stress measured at sample failure, and the bulk (compressive) modulus was calculated as the slope of the initial linear portion of the stress-strain curve. Bulk modulus and compressive strength are presented as mean \pm standard deviation of triplicate samples.

\section{rhBMP-2 release kinetics}

LV/CM scaffolds ( $50 \mathrm{mg}, n=3)$ loaded with rhBMP-2 (100 $\mu \mathrm{g}$ rhBMP-2/mL scaffold) were incubated in $1 \mathrm{~mL}$ $\alpha$-Minimum Essential Medium with $1 \%$ bovine serum albumin at $37{ }^{\circ} \mathrm{C}$ [24]. Elution media was collected and replenished daily to minimize rhBMP-2 degradation. The concentration of rhBMP-2 was measured for 14 days using a human recombinant BMP-2 Quantikine ELISA kit (R\&D systems, Minneapolis, MN).

\section{Rabbit model of posterolateral fusion: pilot study}

All animal procedures were approved by the Institutional Animal Care and Use Committee of the US Army Institute of Surgical Research, Fort Sam Houston, TX, and were conducted in compliance with the Animal Welfare Act, the implementing Animal Welfare Regulations, and the principles of the Guide for the Care and Use of Laboratory Animals. Prior to surgery, the individual components of the LV-PUR/ceramic composite grafts were gamma-irradiated at a dose of $25 \mathrm{kGY}$ to ensure sterility. Six skeletally mature rabbits $(4.35 \pm 0.49 \mathrm{~kg})$ received a single level, bilateral, posterolateral fusion [25]. Approximately $30 \mathrm{~min}$ prior to surgery, a fentanyl patch $(25 \mu \mathrm{g} / \mathrm{kg})$ was affixed to a shaved portion of the rabbit's dorsum and a pre-emptive dose of hydromorphone $(0.15 \mathrm{mg} / \mathrm{kg})$ was given. Anesthesia was induced with ketamine and xylazine (25 and $5 \mathrm{mg} / \mathrm{kg}$ ) and maintained with isoflurane. A dorsal midline skin incision was made over the spinous processes from L4-L7 followed two paramedian fascial incisions. The longissimus muscles were retracted to expose the medial aspect of the transverse processes of L5 and L6. The transverse processes were decorticated with an electric burr. Following exposure, the LVPUR/ceramic composite components were mixed along with the rhBMP-2 $(430 \mu \mathrm{g} / \mathrm{mL}$ cured graft $)$ and ceramic particles (CM or $\mathrm{BG})$, packed into a syringe, and injected onto the site over the intertransverse ligament spanning the L5 and L6 transverse processes (Table 1). The injected composite expanded to a final volume of $\sim 3 \mathrm{~mL}$ per fusion site after the reaction was complete. The incisions were approximated and the animals recovered following computed tomography (CT; Prime Aquilion TSX-303A, Toshiba, Tokyo, Japan). CT scans were performed immediately postoperative and at 4- and 8-week post-operative with slice thickness of $0.5 \mathrm{~mm}$. The rabbits were anesthetized and euthanized after 8 weeks. The spinal segments from L4-L7 were excised and evaluated for fusion by manual palpation, plain radiography (Faxitron MX20), and CT by skilled outside observers, including an orthopedic surgical resident and clinical veterinarian. Motion of the L5-L6 segment was determined by gentle flexion and extension of the fusion site. A successful fusion was specified as cases where no movement at the intervertebral disc was present. The excised spines were fixed in $10 \%$ formalin prior to analysis by microcomputed tomography $(\mu \mathrm{CT})$ and histology.

\section{$\mu C T$ analysis}

The excised spinal segments were cut along the sagittal plane to separate the left and right fusion bodies. A $\mu$ CT50 (SCANCO Medical, Basserdorf, Switzerland) was used to acquire scans of the excised spines at $70 \mathrm{kVp}$ energy, $200 \mu \mathrm{A}$ source current, 1000 projections per rotation, $800 \mathrm{~ms}$ integration time, and an isotropic voxel size of $24.2 \mu \mathrm{m}$. The ossified tissue was segmented from soft tissue using the lower and upper threshold of 240 and $1000 \mathrm{mgHAcm}^{-3}$, respectively, with a Gaussian noise filter settings of sigma 0.7 and support 2. Bone volume/total volume (BV/TV), trabecular number (TB.N.), trabecular thickness (Tb.Th.), and trabecular separation (Tb.Sp.) within the regions of interest were computed using SCANCO's Medical $\mu \mathrm{CT}$ systems software as described previously [26].

\section{Histology and histomorphometry}

After fixation in formalin, the excised spinal halves were dehydrated in a graded series of ethanol and embedded in polymethylmethacrylate (PMMA). Using an Exakt band saw (Exakt Technologies, Oklahoma City, OK), transverse sections were cut. The sections were then ground and polished to $<100 \mu \mathrm{m}$ using an Exakt

Table 1 In vivo study design and LV-PUR/ceramic composite characteristics

\begin{tabular}{|c|c|c|c|c|}
\hline $\begin{array}{l}\text { Treatment } \\
\text { group }\end{array}$ & Ceramic component & $\begin{array}{l}\text { Particle } \\
\text { diameter } \\
(\mu \mathrm{m})\end{array}$ & $\begin{array}{l}\text { Ceramic } \\
\text { composition } \\
(w t \%)\end{array}$ & Number \\
\hline LV/BG & Bioglass (45S5) & $150-212$ & 45 & 3 \\
\hline LV/CM & $\begin{array}{l}\text { 85/15 } \beta \text {-tricalcium } \\
\text { phosphate/ } \\
\text { hydroxyapatite ceramic }\end{array}$ & $100-500$ & 45 & 3 \\
\hline
\end{tabular}

Data are shown as mean \pm SD 


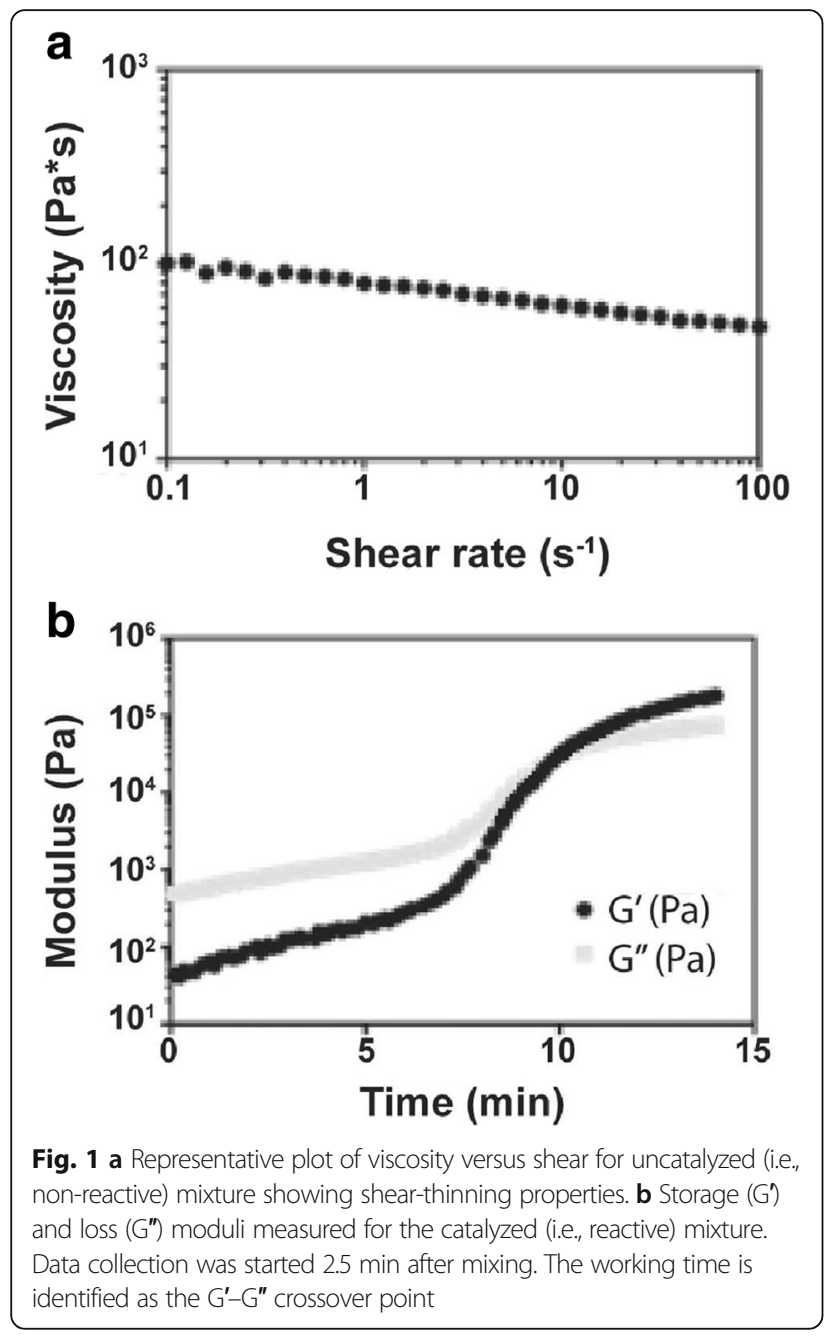

grinding system and stained with Sanderson's rapid bone stain. New bone stained red, residual CM stained black, and infiltrating cells stained blue. Remaining BG particles appeared white and did not absorb the stain. Histological sections were used to visualize the amount of new bone formed in the fusion body and the residual $\mathrm{CM}$ and BG particles. MetaMorph software (Molecular Devices, Sunnyvale, CA) was used to quantify the area of the bone in the fusion mass. The color threshold was set to account for the red stain (new bone), and the threshold settings were identical for all images. The area of interest was selected to include the fusion mass only and

Table 2 Characteristics and mechanical properties of LV-PUR/ ceramic composite bone grafts

\begin{tabular}{lllll}
\hline $\begin{array}{l}\text { Treatment } \\
\text { group }\end{array}$ & $\begin{array}{l}\text { Pore size } \\
(\mu \mathrm{m})\end{array}$ & $\begin{array}{l}\text { Porosity } \\
(\text { vol\%) }\end{array}$ & $\begin{array}{l}\text { Bulk modulus } \\
(\mathrm{MPa})\end{array}$ & Yield strength (MPa) \\
\hline LV/BG & $89 \pm 2$ & $52.4 \pm 0.3$ & $1.2 \pm 0.1$ & $0.37 \pm 0.03$ \\
LV/CM & $100 \pm 1^{*}$ & $48.0 \pm 3.0$ & $3.1 \pm 0.4^{*}$ & $0.38 \pm 0.05$ \\
\hline
\end{tabular}

Data are shown as mean \pm SD

*Statistical significance $(p=0.05)$

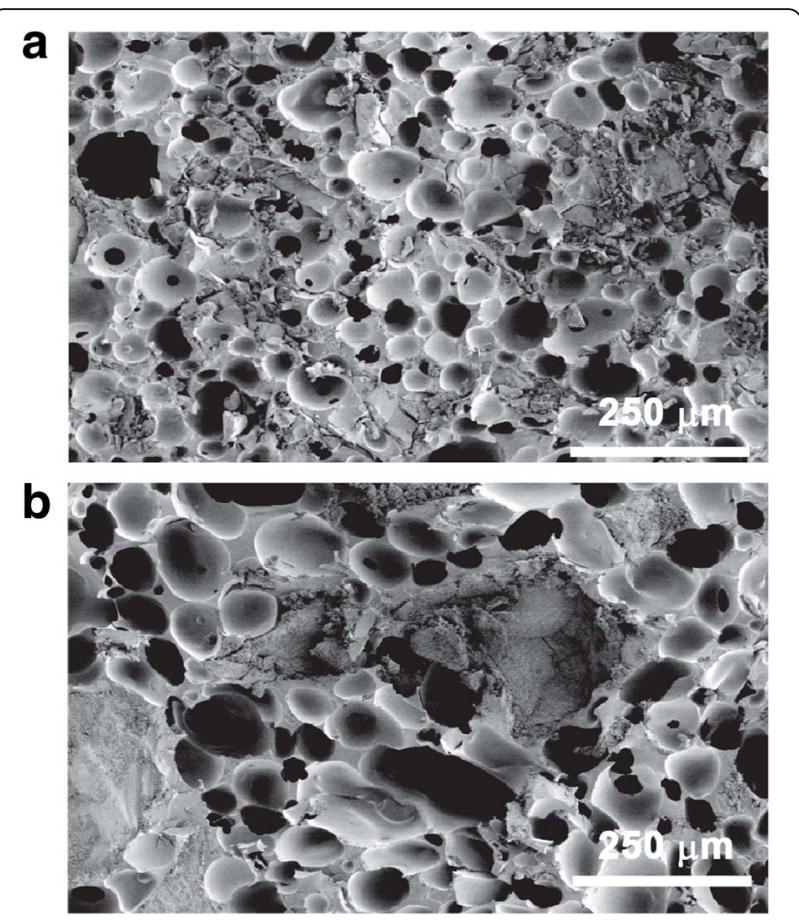

Fig. 2 Scanning electron micrographs of $\mathbf{a} L V / B G$ and $\mathbf{b}$ LV/CM composites

excluded regions outside the plane of the lateral processes.

\section{Statistical analysis}

Data are plotted as mean \pm standard deviation. Comparisons between groups were performed using unpaired $t$ tests in GraphPad Prism (Graph Pad, La Jolla, CA). The significance level was defined as $p<0.05$.

\section{Results}

\section{Material properties}

The LV/BG composite exhibited rheological properties optimal for injectable/settable materials. It expressed

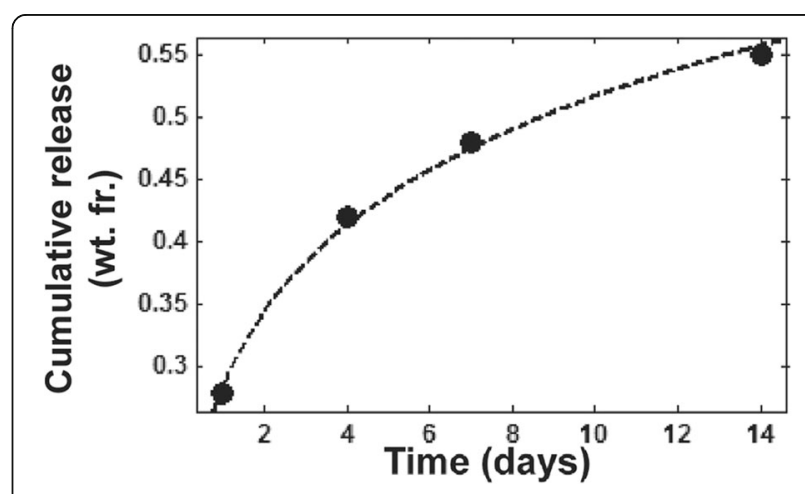

Fig. 3 Cumulative fractional release of rhBMP-2 from LV/CM scaffolds measured by ELISA 
shear-thinning properties, with an initial viscosity of $65.7 \pm 4.1 \mathrm{~Pa} \mathrm{~s}$ and a working time of $11.5 \pm 0.3 \mathrm{~min}$, as determined by the crossover of the storage and loss moduli (Fig. 1a, b). It was not possible to test LV/CM composites due to the larger size of the particles (100$500 \mu \mathrm{m})$ and granularity of the mixture. The TFT of LV/ BG and LV/CM were $10.3 \pm 0.8$ and $9.6 \pm 0.5 \mathrm{~min}$. The porosity was similar for the two ceramic composite groups (Table 2); however, SEM analysis revealed a modest, but significant, increase in pore size for the LV/CM composites (Table 2, Fig. 2a, b). Interestingly, despite the larger pore size, the LV/CM had a higher bulk moduli at

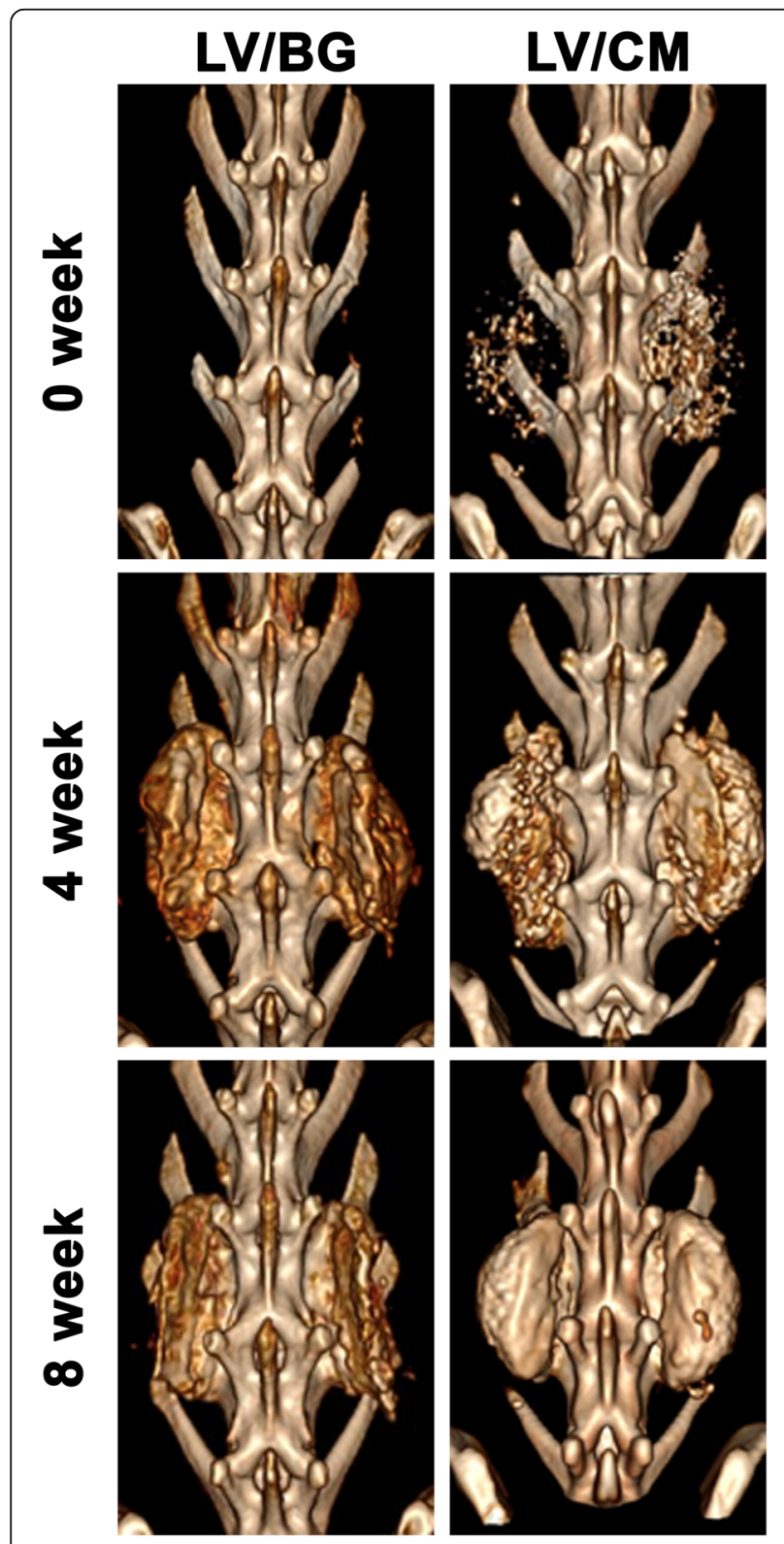

Fig. 4 Representative 3D renderings of $C T$ scans taken at 0 (post-operative), 4, and 8 weeks after implantation of the bone graft at the fusion site for LV/BG and LV/CM ceramic composites

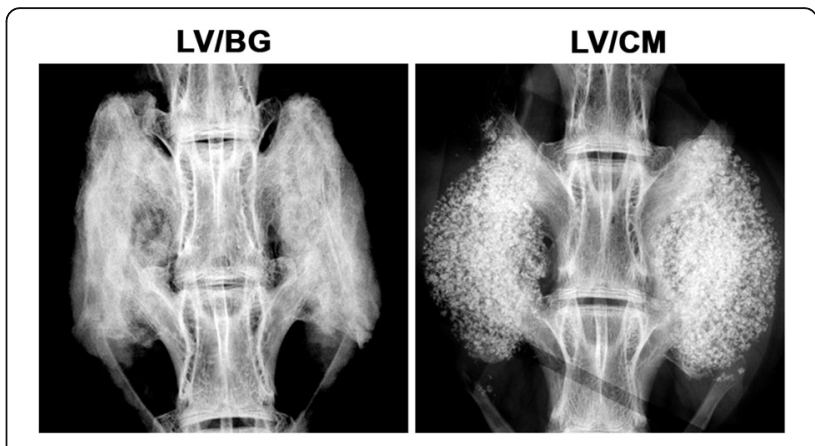

Fig. 5 Representative plain radiographs of rabbit spinal fusion sites at 8 weeks for LV/BG and LV/CM ceramic composites

3.2 MPa than the LV/BG at 1.2 MPa. rhBMP-2 continued to release from LV/CM steadily over a 14-day period (Fig. 3). Approximately 55\% of the rhBMP-2 was released after 2 weeks.

\section{Posterolateral fusion model}

Complete fusion was measured in all animals (3/3) in both treatment groups as determined by manual palpation of the fusion body immediately after the samples

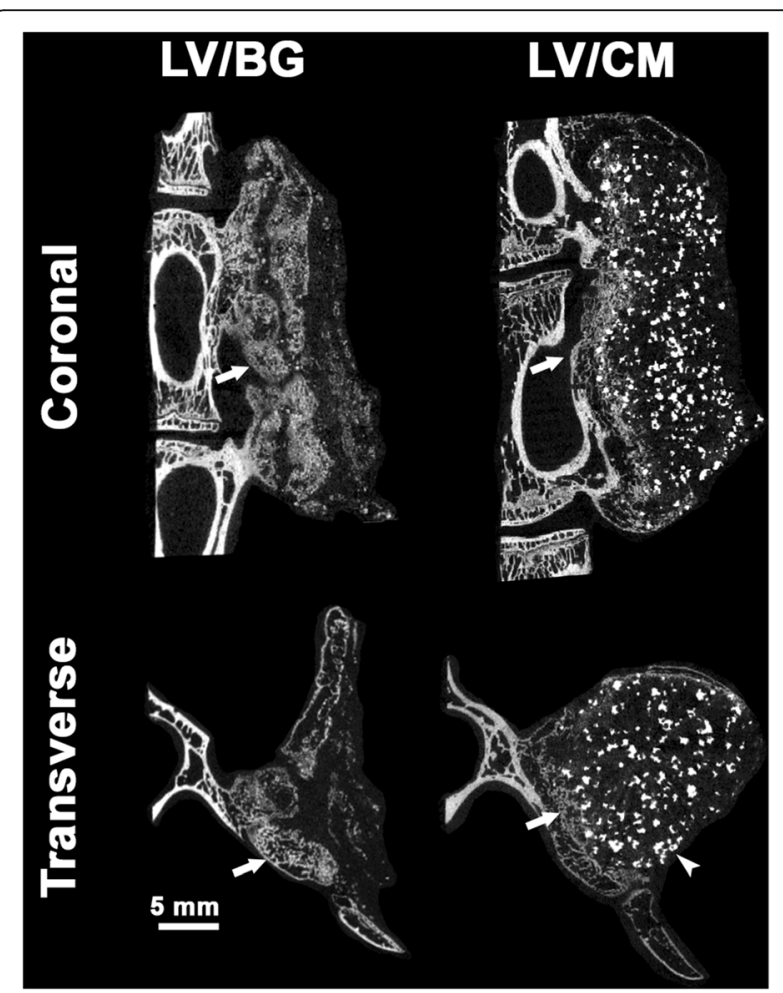

Fig. 6 Representative $\mu C T$ images of LV/BG and LV/CM ceramic composites in the coronal and transverse planes. New bone formation (arrow) is noted adjacent to the vertebral body. While the BG particles are indistinguishable from new bone, residual CM appear as bright spots (arrow head) in both coronal and transverse view (scale bar $=5 \mathrm{~mm}$ ) 
were explanted. All samples showed a visual and progressive increase in bone volume over the 8-week study (Fig. 4). The CM component is radiopaque, therefore visible in the initial, 0 week CT. Using plain radiography, new bone formation is evident in the LV/BG group with substantial bone formation on both sides of the fusion site (Fig. 5). Residual CM is visible as bright white particles of the LV/CM composites. $\mu \mathrm{CT}$ images also indicated new bone formation in both the LV/BG and LV/ $\mathrm{CM}$ groups between the transverse processes, as well as expansion of the composites outside the paraspinal bed (Fig. 6). As with plain radiography, residual CM is visible as bright white particles in the $\mu \mathrm{CT}$ images. Taken together, these radiographic images provide evidence of bone formation and spinal fusion between L5 and L6, which is consistent with the manual palpation data.

Histology confirms bone formation within the fusion sites from both the LV/BG (Fig. 7) and the LV/CM (Fig. 8) composites. New bone (red) has forms adjacent to the vertebral body, spanning the distance between the transverse processes. There is more evidence of host infiltration, cells, and fibrous tissue, when LV/BG was implanted compared to the LV/CM, coinciding with visually inspected smaller quantities of the ceramic component in the LV/BG group. While there is less evidence of infiltration and ceramic resorption in the LV/CM group, as indicated by the numerous opaque areas, there is evidence of new bone formation at the graft/host interface. Also, the LV/CM group maintained the original graft space whereas the fast LV/BG group reduced in size, indicating quicker graft resorption. No significant difference in total bone area was observed between the LV/BG and LV/CM groups.

\section{Discussion}

LV-PUR/ceramic composites augmented with $430 \mu \mathrm{g} /$ $\mathrm{mL}$ rhBMP-2 exhibited compression resistance, supported diffusion-controlled release of rhBMP-2, and promoted new bone formation and spinal fusion in a PLF in a rabbit model. The properties of the LV-PUR/ceramic composites were favorable for an injectable application, such as MIS, by maintaining low viscosity for close to $10 \mathrm{~min}$. Upon setting, the composites expressed compression resistance with bulk moduli greater than $1 \mathrm{MPa}$, thus predicted to withstand the compressive forces of the local musculature. Three modes of

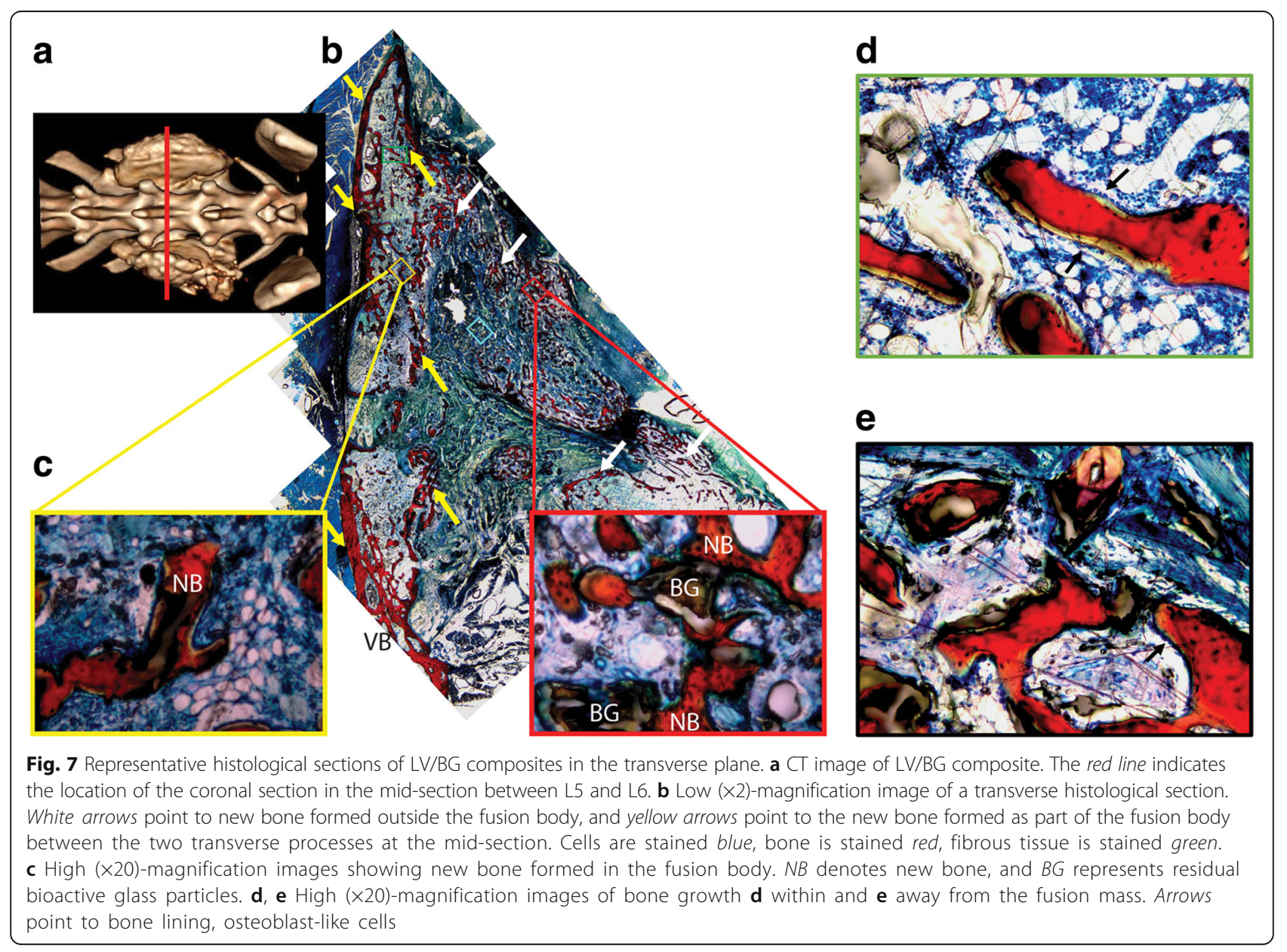




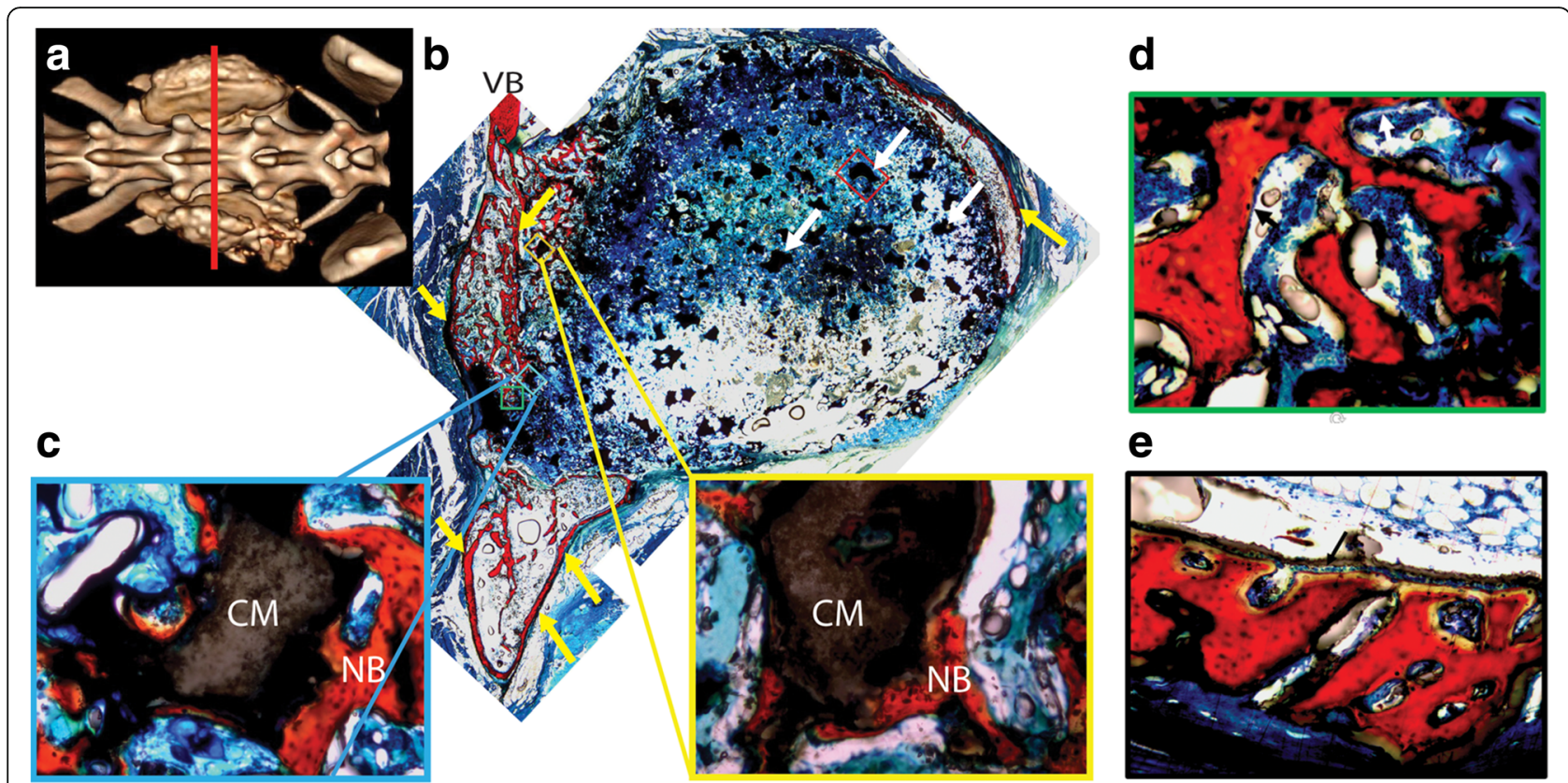

Fig. 8 Representative histological sections of LV/CM composites in the transverse plane. a CT image of LV/CM composite. The red line indicates the location of the coronal section in the mid-section between L5 and L6. b Low (×2)-magnification image of a transverse histological section. White arrows point to residual CM particles, and yellow arrows point to the new bone formed as part of the fusion body between the two transverse processes at the mid-section. Cells are stained blue, residual MG is black, bone is red, and fibrous tissue is green. c High $(\times 20)$-magnification images showing new bone formation on the surface of the CM particles. NB denotes new bone, and CM represents residual ceramic particles. $\mathbf{d}$, e High (×20)-magnification images of bone growth $\mathbf{d}$ within and e away from the fusion mass. Arrows point to bone lining, osteoblast-like cells

measurement confirmed fusion in all animals of both groups, and this, while a small group size, can be interpreted positively [13].

An injectable, settable, and compression-resistant carrier for rhBMP-2 administered by MIS techniques has been postulated to decrease complications and length of hospital stays [27]. While injectable and compressionresistant carriers have been reported to maintain space and prevent soft tissue prolapse in a canine mandibular ridge model [16], these carriers have not been evaluated in a more stringent preclinical PLF model. Thus, the aim of this pilot study was to introduce and evaluate injectable, settable, and compression-resistant LV-PUR ceramic carriers for rhBMP-2 for spinal arthrodesis. Ideally, an rhBMP-2 bone graft substitute for MIS applications for PLF should have several characteristics: low viscosity for injectability, a reasonable working time, a compression-resistant matrix, steady rhBMP-2 release, and a resorption rate that matches new bone formation. Several products, both in the market and under investigation, have addressed a number but not all these characteristics. Gold standard rhBMP-2 delivery for lumbar arthrodesis is via an ACS. While the ACS carrier retains rhBMP-2 at the site of placement for 2 weeks [28], the ACS carrier is ineffective for PLF at clinically relevant doses due to soft tissue compression of the collagen [29]. A compression-resistant collagen/ceramic (85/15 $\beta$ -
TCP/HA) matrix (CRM) augmented with $430 \mu \mathrm{g} / \mathrm{mL}$ rhBMP-2 resulted in successful fusion in a rabbit arthrodesis modal, as determined by manual palpation and radiography [30]. This CRM carrier also promoted fusion in non-human primate models of PLF [8, 9], and patients treated with the CRM carrier exhibited superior fusion at 1 year as compared to patients treated with autograft [10]. The relatively high [31] bulk modulus of the CRM resisted the compressive forces of the musculature, resulting in enhanced fusion. These studies also demonstrated that that fusion mass could be augmented by increasing the volume of the carrier and identified the concentration of rhBMP-2 defined on the basis of carrier volume as a critical variable [10]. However, the CRM matrix is not injectable and therefore cannot be combined with MIS surgical techniques. In the present study, LV grafts augmented with the recommended concentration for the ACS carrier in rabbits $(430 \mu \mathrm{g}$ rhBMP-2/mL defined on graft volume) supported spinal fusion in a pilot study of rabbit PLF. These findings are consistent with a previous study that reported that LV bone grafts augmented with $400 \mu \mathrm{g}$ rhBMP-2/mL supported new bone formation and preserved the anatomy of the mandibular ridge in a canine model [16]. While space maintenance cannot be assessed in the rabbit PLF model, the relatively high bulk modulus of LV-PUR grafts, which is comparable to that of the CRM, suggests 
that these carriers would be compression-resistant in primates and humans.

This pilot study was designed to answer the question whether injectable, settable, and compression-resistant low-viscosity poly(ester urethane)/ceramic composite grafts augmented with rhBMP-2 could promote fusion in a single-level rabbit PLF model. No differences in fusion rates $(100 \%)$ or new bone area were observed between groups, which may be due in part to the small sample size ( $n=3$ per group). When used in this model, autograft has a fusion rate of $66 \%$ and rhBMP-2-loaded ACS has a fusion rate of $100 \%$ but at increased concentrations [7, 25]. Additional dose-response studies with larger sample sizes and clinical controls are needed to establish that the LV-PUR/ceramic composite carriers are equivalent to the ACS carrier at comparable doses of rhBMP-2. The favorable combination of injectability, settability, compression-resistant mechanical properties, and sustained release of rhBMP-2 highlights the potential of LV-PUR/ceramic composite carriers for spinal fusion procedures using MIS techniques.

\section{Conclusion}

In this study, we investigated injectable and settable LV polymer/composite bone grafts as injectable, compression-resistant carriers for rhBMP-2 in a single-level rabbit PLF model. Successful fusion was achieved in animals treated with either LV/CM or LV/BG composites, as evidenced by manual palpation. Images of $\mu \mathrm{CT}$ and histological sections revealed evidence of bone fusion near the TPs. This study highlights the potential of LV grafts augmented with rhBMP-2 as injectable bone grafts for MIS posterolateral spinal fusion surgeries.

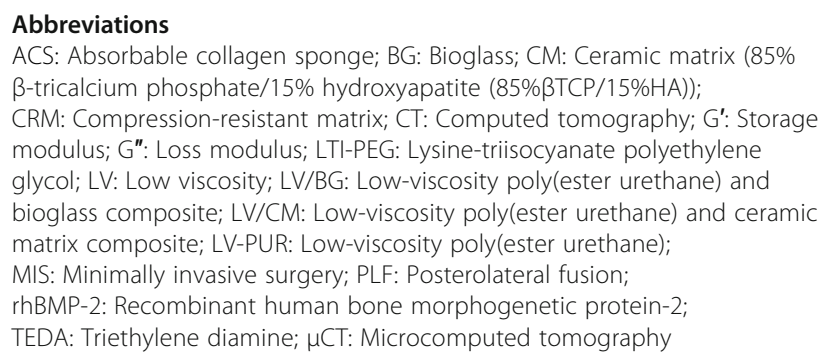

\section{Abbreviations}

ACS: Absorbable collagen sponge; BG: Bioglass; CM: Ceramic matrix (85\% $\beta$-tricalcium phosphate/15\% hydroxyapatite $(85 \% \beta T C P / 15 \% H A))$; CRM: Compression-resistant matrix; CT: Computed tomography; G': Storage modulus; G": Loss modulus; LTI-PEG: Lysine-triisocyanate polyethylene glycol; LV: Low viscosity; LV/BG: Low-viscosity poly(ester urethane) and bioglass composite; LV/CM: Low-viscosity poly(ester urethane) and ceramic matrix composite; LV-PUR: Low-viscosity poly(ester urethane); MIS: Minimally invasive surgery; PLF: Posterolateral fusion; rhBMP-2: Recombinant human bone morphogenetic protein-2; TEDA: Triethylene diamine; $\mu \mathrm{CT}$ : Microcomputed tomography

\section{Acknowledgements}

Anne Talley acknowledges the support from the Department of Education for a Graduate Assistance in Areas of National Need Fellowship under grant number P200A090323. Partial financial support was provided by the US Army Institute of Surgical Research (Fort Sam Houston, TX), and rhBMP-2 was provided as a gift by Medtronic Spinal and Biologics.

\section{Funding}

This work was supported by the Army, Navy, NIH, Air Force, VA, and Health Affairs to support the AFIRM II effort, under award no. W81XWH-14-2-0004. The US Army Medical Research Acquisition Activity, 820 Chandler Street, Fort Detrick MD 21702-5014, is the awarding and administering acquisition office. Instrumentation for $\mu \mathrm{CT}$ analysis was purchased with funds from $\mathrm{NIH}$ grant S10RR027631.

\section{Availability of data and materials}

The datasets supporting the conclusions of this article are included with the article.

\section{Disclaimer}

Opinions, interpretations, conclusions, and recommendations are those of the author and are not necessarily endorsed by the Department of Defense.

\section{Author's contributions}

SMS contributed to the in vivo study design, execution, data analysis, and final drafting of the manuscript. ADT contributed to the development and assessment of the materials, the in vivo study design, data analysis, and final drafting of the manuscript. MAPM and KJZ contributed to the preparation and assessment of the materials. KK and DS contributed to the material design and uses. SAG and JCW obtained funding and contributed to the overall study design and drafting of the manuscript. All authors read and approved the final manuscript.

\section{Ethics approval}

All animal procedures were approved by the Institutional Animal Care and Use Committee of the US Army Institute of Surgical Research, Fort Sam Houston, TX, and were conducted in compliance with the Animal Welfare Act, the implementing Animal Welfare Regulations, and the principles of the Guide for the Care and Use of Laboratory Animals.

\section{Consent for publication}

Not applicable.

\section{Competing interests}

Authors KK and DS are employees of Medtronic Spinal and Biologics. The other remaining authors declare that they have no competing interests.

\section{Author details}

'US Army Institute of Surgical Research, Fort Sam Houston, TX, USA. ${ }^{2}$ Department of Chemical and Biomolecular Engineering, Vanderbilt University, Nashville, TN, USA. ${ }^{3}$ Department of Biomedical Engineering, Vanderbilt University, Nashville, TN, USA. ${ }^{4}$ Medtronic Spine LLC, Memphis, TN, USA. ${ }^{5}$ Center for Bone Biology, Vanderbilt University Medical Center, Nashville, TN, USA.

Received: 23 May 2017 Accepted: 28 June 2017

Published online: 11 July 2017

\section{References}

1. Wang MC, Chan L, Maiman DJ, Kreuter W, Deyo RA. Complications and mortality associated with cervical spine surgery for degenerative disease in the United States. Spine (Phila Pa 1976). 2007;32(3):342-7.

2. Lad SP, Nathan JK, Boakye M. Trends in the use of bone morphogenetic protein as a substitute to autologous iliac crest bone grafting for spinal fusion procedures in the United States. Spine (Phila Pa 1976). 2011;36(4):E274-281.

3. Burkus JK, Gornet MF, Dickman CA, Zdeblick TA. Anterior lumbar interbody fusion using rhBMP-2 with tapered interbody cages. J Spinal Disord Tech. 2002;15(5):337-49.

4. Boden SD, Zdeblick TA, Sandhu HS, Heim SE. The use of rhBMP-2 in interbody fusion cages: definitive evidence of osteoinduction in humans: a preliminary report. Spine (Phila Pa 1976). 2000;25(3):376-81.

5. McKay B, Sandhu HS. Use of recombinant human bone morphogenetic protein-2 in spinal fusion applications. Spine (Phila Pa 1976). 2002;27(16 Suppl 1):S66-85.

6. David SM, Gruber HE, Meyer Jr RA, Murakami T, Tabor OB, Howard BA, et al. Lumbar spinal fusion using recombinant human bone morphogenetic protein in the canine. A comparison of three dosages and two carriers. Spine (Phila Pa 1976). 1999;24(19):1973-9.

7. Schimandle JH, Boden SD, Hutton WC. Experimental spinal fusion with recombinant human bone morphogenetic protein-2. Spine. 1995;20(12):1326-37.

8. Akamaru T, Suh D, Boden SD, Kim HS, Minamide A, Louis-Ugbo J. Simple carrier matrix modifications can enhance delivery of recombinant human bone morphogenetic protein-2 for posterolateral spine fusion. Spine (Phila Pa 1976). 2003;28(5):429-34

9. Suh DY, Boden SD, Louis-Ugbo J, Mayr M, Murakami H, Kim HS, et al. Delivery of recombinant human bone morphogenetic protein-2 using a 
compression-resistant matrix in posterolateral spine fusion in the rabbit and in the non-human primate. Spine (Phila Pa 1976). 2002;27(4):353-60.

10. Glassman SD, Dimar JR, Carreon LY, Campbell MJ, Puno RM, Johnson JR. Initial fusion rates with recombinant human bone morphogenetic protein-2/ compression resistant matrix and a hydroxyapatite and tricalcium phosphate/ collagen carrier in posterolateral spinal fusion. Spine (Phila Pa 1976). 2005;30(15):1694-8.

11. Dumas JE, Zienkiewicz K, Tanner SA, Prieto EM, Bhattacharyya S, Guelcher SA. Synthesis and characterization of an injectable allograft bone/polymer composite bone void filler with tunable mechanical properties. Tissue Eng Part A. 2010;16(8):2505-18

12. Bonzani IC, Adhikari R, Houshyar S, Mayadunne R, Gunatillake P, Stevens MM. Synthesis of two-component injectable polyurethanes for bone tissue engineering. Biomaterials. 2007;28(3):423-33.

13. Page JM, Prieto EM, Dumas JE, Zienkiewicz KJ, Wenke JC, Brown-Baer P, et al. Biocompatibility and chemical reaction kinetics of injectable, settable polyurethane/allograft bone biocomposites. Acta Biomater. 2012;8(12):4405-16.

14. Prieto EM, Talley AD, Gould NR, Zienkiewicz KJ, Drapeau SJ, Kalpakci KN, et al. Effects of particle size and porosity on in vivo remodeling of settable allograft bone/polymer composites. J Biomed Mater Res B Appl Biomater. 2015;103(8):1641-51.

15. Dumas JE, Prieto EM, Zienkiewicz KJ, Guda T, Wenke JC, Bible J, et al. Balancing the rates of new bone formation and polymer degradation enhances healing of weight-bearing allograft/polyurethane composites in rabbit femoral defects. Tissue Eng Part A. 2014;20(1-2):115-29.

16. Talley AD, Kalpakci KN, Shimko DA, Zienkiewicz KJ, Cochran DL, Guelcher SA. Effects of recombinant human bone morphogenetic protein-2 dose and ceramic composition on new bone formation and space maintenance in a canine mandibular ridge saddle defect model. Tissue Eng Part A. 2016;22(5-6):469-79.

17. Brown KV, Li B, Guda T, Perrien DS, Guelcher SA, Wenke JC. Improving bone formation in a rat femur segmental defect by controlling bone morphogenetic protein-2 release. Tissue Eng Part A. 2011;17(13-14):1735-46.

18. Guelcher S, Srinivasan A, Hafeman A, Gallagher K, Doctor J, Khetan S, et al. Synthesis, in vitro degradation, and mechanical properties of two-component poly(ester urethane)urea scaffolds: effects of water and polyol composition. Tissue Eng. 2007;13(9):2321-33.

19. Guelcher SA, Patel V, Gallagher KM, Connolly S, Didier JE, Doctor JS, et al. Synthesis and in vitro biocompatibility of injectable polyurethane foam scaffolds. Tissue Eng. 2006;12(5):1247-59.

20. Harmata AJ, Ward CL, Zienkiewicz KJ, Wenke JC, Guelcher SA. Investigating the effects of surface-initiated polymerization of $\varepsilon$-caprolactone to bioactive glass particles on the mechanical properties of settable polymer/ceramic composites. J Mater Res. 2014;29(20):2398-407.

21. Jiang G, Evans M, Jones I, Rudd C, Scotchford C, Walker G. Preparation of poly ( $\varepsilon$-caprolactone)/continuous bioglass fibre composite using monomer transfer moulding for bone implant. Biomaterials. 2005;26(15):2281-8.

22. Verné E, Vitale-Brovarone C, Bui E, Bianchi C, Boccaccini A. Surface functionalization of bioactive glasses. J Biomed Mater Research A. 2009;90(4):981-92.

23. Talley AD, McEnery MA, Kalpakci KN, Zienkiewicz KJ, Shimko DA, Guelcher SA. Remodeling of injectable, low-viscosity polymer/ceramic bone grafts in a sheep femoral defect model. J Biomed Mater Res B Appl Biomater. 2016. Epub Ahead of Print.

24. Li B, Yoshii T, Hafeman AE, Nyman JS, Wenke JC, Guelcher SA. The effects of rhBMP-2 released from biodegradable polyurethane/microsphere composite scaffolds on new bone formation in rat femora. Biomaterials. 2009;30(35):6768-79.

25. Boden SD, Schimandle JH, Hutton WC. An experimental lumbar intertransverse process spinal fusion model: radiographic, histologic, and biomechanical healing characteristics. Spine (Phila Pa 1976). 1995;20(4):412-20.

26. Bouxsein ML, Boyd SK, Christiansen BA, Guldberg RE, Jepsen K, Muller R. Guidelines for assessment of bone microstructure in rodents using micro-computed tomography. J Bone Miner Res. 2010;25(7):1468-86.

27. Skovrlj B, Gilligan J, Cutler HS, Qureshi SA. Minimally invasive procedures on the lumbar spine. World J Clin Cases. 2015;3(1):1-9.

28. Li RH, Wozney JM. Delivering on the promise of bone morphogenetic proteins. Trends Biotechnol. 2001;19(7):255-65.

29. Martin Jr GJ, Boden SD, Morone MA, Moskovitz PA. Posterolateral intertransverse process spinal arthrodesis with rhBMP-2 in a nonhuman primate: important lessons learned regarding dose, carrier, and safety. J Spinal Disord. 1999;12(3):179-86.
30. Kraiwattanapong C, Boden SD, Louis-Ugbo J, Attallah E, Barnes B, Hutton WC Comparison of Healos/bone marrow to INFUSE (rhBMP-2/ACS) with a collagen-ceramic sponge bulking agent as graft substitutes for lumbar spine fusion. Spine (Phila Pa 1976). 2005;30(9):1001-7.

31. Alpert S. AMPLIFY(TM) rhBMP-2 matrix, FDA Orthopaedic and Rehabilitation Devices Advisory Panel. 2010. p. 103.

\section{Submit your next manuscript to BioMed Central and we will help you at every step:}

- We accept pre-submission inquiries

- Our selector tool helps you to find the most relevant journal

- We provide round the clock customer support

- Convenient online submission

- Thorough peer review

- Inclusion in PubMed and all major indexing services

- Maximum visibility for your research

Submit your manuscript at www.biomedcentral.com/submit
Biomed Central 